\title{
TEIKNIK PENANGKAPAN IKAN SIDAT (Anguilla spp.) DI SUNGAI KETAHUN PROPINSI BENGKULU
}

\author{
Syamsul Bahri ${ }^{*}$ \\ "Teknisi Litkayasa pada Balai Riset Perikanan Perairan Umum, Palembang
}

\section{PENDAHULUAN}

Sungai Ketahun merupakan sungai yang terpanjang di Propinsi Bengkulu, bagian hilirnya bermuara di Samudera Indonesia dan bagian hulunya berada pada kaki Bukit Barisan dekat Desa Kota Donok dan Danau Tes termasuk wilayah Kecamatan Lebong Selatan Propinsi Bengkulu (Gambar 1). Aktivitas penangkapan ikan sidat terdapat di wilayah Sungai Ketahun bagian hulu di Kecamatan Lebong Selatan.

Ikan sidat (Anguilla spp.) merupakan jenis ikan yang bernilai ekonomis penting di pasaran internasional, baik dalam ukuran benih (elver), fingerling maupun yang berukuran dewasa. Ikan sidat termasuk golongan ikan "katadromous", yaitu ikan yang pada saat tumbuh dan membesarkan diri berlangsung di air tawar, saat memijah dan melakukan migrasi menuju ke laut (Kottelat et al., 1993). Ikan sidat juga tergolong ikan buas dengan makanan utamanya adalah ikan (Samuel et al., 1998). Ikan sidat banyak tersebar di beberapa pulau di Indonesia antara lain sepanjang pantai barat Pulau Sumatera, pantai selatan Pulau Jawa, Pulau Sulawesi, dan Irian bagian utara.

Alat tangkap yang dipergunakan oleh petani/nelayan di wilayah ini masih tergolong alat tangkap tradisional seperti lumpatan, bubu, pancing, dan rawai dasar. Kinerja alat tersebut umumnya masih belum baik dan produktivitasnya rendah (Anung \& Barus, 1995); Brand, 1972 mengklasifikasikan alat tangkap menjadi 16 golongan, antara lain: pancing dan rawai tergolong fishing lines yaitu alat penangkapan ikan menggunakan tali pancing, bubu digolongkan ke dalam fishing with trap yaitu menangkap ikan dengan cara memerangkapnya, sedangkan tombak dapat digolongkan ke dalam fishing with wounding gears yaitu menangkap

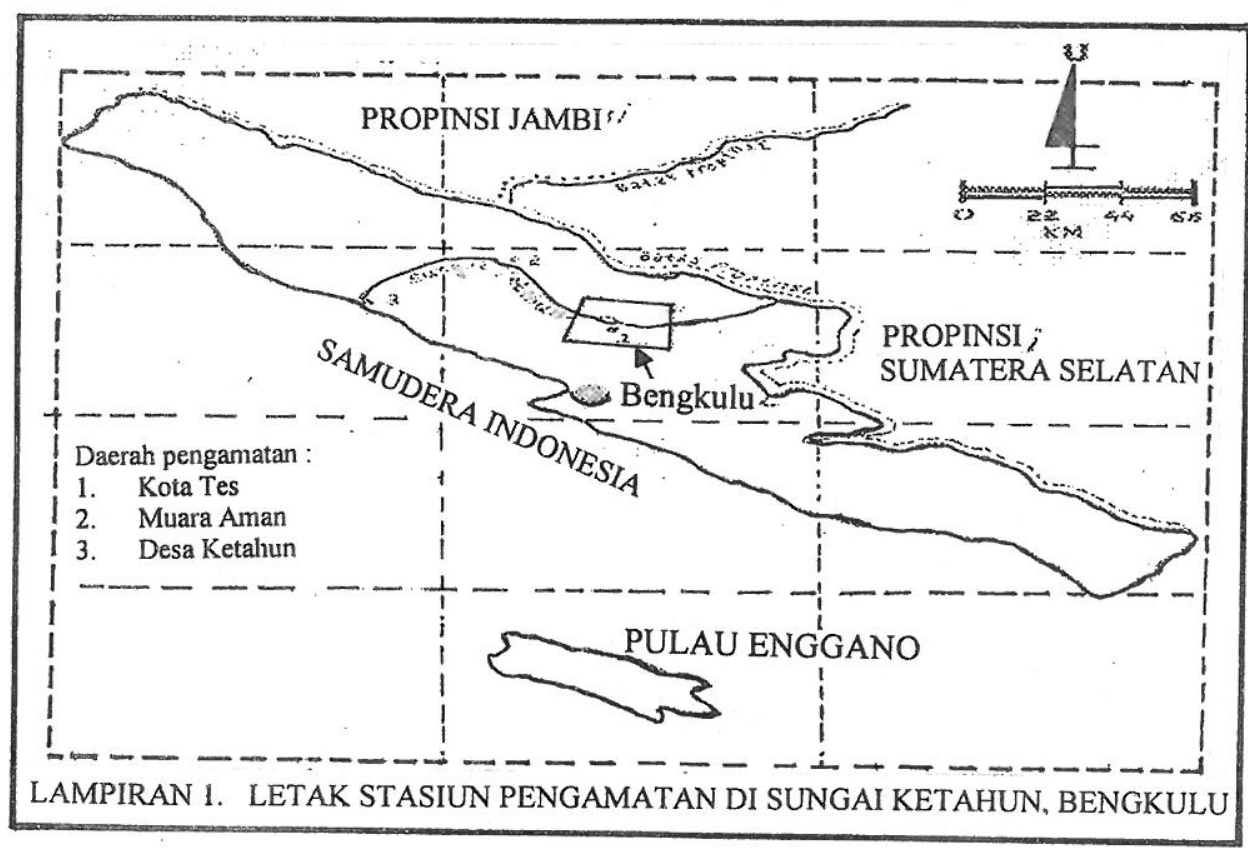

Gambar 1. Peta lokasi pengamatan penangkapan ikan sidat (Anguilla spp). 
ikan dengan cara melukai tubuh ikan. Tulisan ini bertujuan untuk mengetahui teknik penangkapan ikan sidat dengan alat tangkap lumpatan yang dipergunakan oleh nelayan di perairan umum Sungai Ketahun bagian hulu Kecamatan Lebong Selatan Propinsi Bengkulu.

\section{POKOK BAHASAN}

\section{Bahan dan Alat}

Bahan yang dipergunakan untuk membuat satu unit alat tangkap lumpatan adalah: 1) papan, 2) kayu sento, 3) paku, 4) tali nilon, 5) bahan penunjang bubu bambu dan unjar.

Alat yang dipergunakan untuk pembuatan alat tangkap lumpatan, adalah: 1) gergaji, 2) pisau, 3) palu, 4) tang penjepit.

\section{Cara Pembuatan}

1. Papan dan kayu sento dipotong atau dibelah sesuai dengan ukuran alat tangkap lumpatan yang akan dibuat.

2. Kayu sento yang sudah dipotong dipaku pada papan, gunanya untuk menstabilkan bentuk alat tangkap tersebut (Gambar 2).

3. Setelah badan alat tangkap lumpatan sudah terbentuk, bagian belakang dipasang alat perangkap (bubu bambu).

4. Perangkap ikan (bubu bambu) dipasang pada bagian ujung alat tangkap lumpatan lalu dijepit dan diikatkan dengan tali nilon.

\section{Aspek Penangkapan}

1. Alat tangkap lumpatan sangat baik dioperasikan di perairan yang arus airnya deras.

2. Pengoperasian alat dilakukan pada musim penghujan sampai awal musim kemarau.

3. Produktivitas alat ini di Sungai Ketahun bagian hulu, tepatnya di bagian hilir bendungan Danau Tes berkisar antara 10-50 ekor/1 alat/malam.

Di Sungai Ketahun bagian hulu ikan sidat yang tertangkap alat lumpatan berukuran induk dan dewasa.

\section{Cara Pengoperasian}

1. Alat tangkap lumpatan dipasang pada bagian tengah badan sungai, bagian muka menghadap arus air. Aktivitas alat tangkap lumpatan akan berfungsi dengan baik, jika arus airnya deras.

2. Alat tangkap tersebut dijepit dengan kayu/unjar dan unjar tersebut ditancapkan pada dasar sungai kemudian alat tersebut diikatkan pada unjar satu persatu, gunanya supaya alat tidak hanyut dibawa arus air.

3. Alat perangkap ikan (bubu bambu) diangkat dan diambil hasilnya dibawa ke daratan sungai pada pagi hari.

4. Hasil perolehan/tangkapan selanjutnya ditampung/dikumpulkan dalam tampungan ikan berupa sangkar, gunanya ikan tetap hidup.

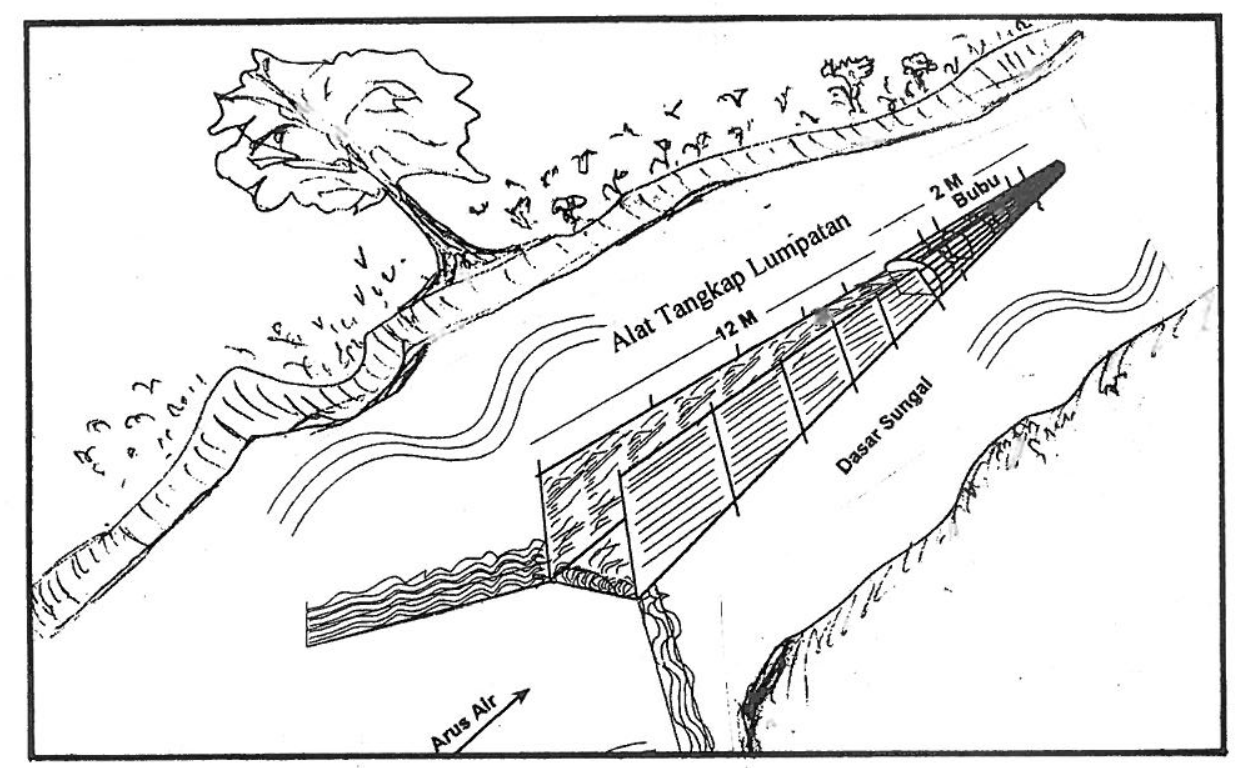

Gambar 2. Alat tangkap lumpatan. 
Tabel 1. Hasil tangkapan ikan sidat dalam satu bulan

\begin{tabular}{clccc} 
No. & & Ukuran ikan (Panjang) & Jumlah (kg) & Keterangan \\
\hline 1. & Induk & $60-90 \mathrm{~cm}$ & 10,080 & Jumlah alat tangkap 12 unit \\
2. & Dewasa & $30-60 \mathrm{~cm}$ & 7,920 & \\
3. & Anak & - & - & \\
\hline & & Jumlah Total & 18,000 & \\
\hline
\end{tabular}

Sumber: Data Primer Tahun 1998

\section{KESIMPULAN}

1. Pengoperasian alat lumpatan harus dilakukan secara hati-hati sebab alat dioperasikan pada arus air yang deras, bebatuan licin, dan agak dalam.

2. Alat ini berguna untuk menambah penghasilan keluarga petani/nelayan.

3. Perlu diwaspadai karena penangkapan ikan sidat memakai alat tangkap lumpatan juga memungkinkan tertangkapnya anak ikan yang bernilai ekonomi seperti ikan sema dan lainlain.

\section{DAFTAR PUSTAKA}

Anung, A. \& H.R. Barus. 1995. Status teknologi penangkapan ikan demersal dan kemungkinan pengembangannya di Kabupaten Lombok Barat. Jurnal Penelitian Perikanan Indonesia
Vol. 1 No. 4 Tahun 1995. Puslitbang Perikanan, Badan Litbang Pertanian, - Departemen Pertanian, Jakarta. Hal: 1-11.

Brandt, A.V. 1972. Revised and enlarged fish catshing methods of the world. Fishing News (Book) Ltd. 23 Rosemount Avenue Weet by Fleet. London EC4. 240 p.

Kottelat, M., J.A Whitten, N. Kartikasari, \& S. Wiryoatmojo. 1993. Freshwater fishes of Western Indonesia and Sulawesi. Periplus Edition and EMDI Project Indonesia, Jakarta. $221 \mathrm{p}$.

Samuel, Ondara, \& S. Adjie. 1998. Beberapa aspek biologi ikan sidat (Anguilla spp.) di DAS Ketahun, Bengkulu. Laporan Teknis 1997/1998, Proyek Penelitian Perikanan Air Tawar pada Lolitkanwar Palembang. 15 hal. 